Culoured Haze around the Moon.

ALL last night there was a very strongly marked circular space of hazy reddish colour about the moon of about $20^{\circ}$ radius; towards morning ( 2 to $4 \mathrm{a} . \mathrm{m}$.) the colour was most pronoinced.

The weather was very fine all night, the temperature being about $20^{\circ} \mathrm{F}$, and the humidity from 30 to 40 per cent. There was yery little haze in the lower atmosphere, the snow on the hill-tops being silvery white to the verge of the horizon, about 50 miles distant. Immediately above the horizon to S.W. there was, at 3 and 4 a.m., a belt of dark copper-coloured sky, the upper edge of which (at 3 a.m.) just touched the lowest part of the coloured space round the moon. There was some cirrus about the moon at times, and on this part of a halo was faintly marked at 2 and 3 a.m. At 4 a.m. filmy cirro-stratus radiating from the south was more general, and the halo was almost complete. The above phenomenon, however, seemed quite different from the ordinary cirrus haze, and so far as could be observed had no trace of either halo or corona connected with it.

Ben Nevis Observatory, February I.

THE NEW EDUCATION AUTHORITY FOR LONDON.

$\mathrm{B} Y$ the provisions of the Education (London) Act, rgo3, which comes into operation on May I next, the control of the education of London becomes a duty of the London County Council. After that date education in London is to be administered as an organic whole and is no longer to consist of separate, unrelated parts. In place of the London School Board administering the elementary education given in schools provided by the ratepayers, the London Technical Education Board regulating the instruction given in accordance with the Technical Instruction Acts, and the governing bodies supervising the work of various grades of secondary schools for boys and girls, the London County Council becomes the authority for the whole of London's education--elementary, secondary, technical and higher.

The Act which brings about this complete and momentous change enacts that the Council shal! establish an education committee in accordance with a scheme made by the Council and approved by the Board of Education. Chiefly with this object in view the London County Council, on November Io last, referred the Education (London) Act, I903, to its General Purposes Committee to advise as to the practical steps to be taken for the administration of the Act. This committee reported to the Council at its meeting held on January 26 , and the report, containing suggestions as to the constitution of the Education Committee which were adopted by a large majority of the Council, deserves the earnest attention of all who have at heart the educational welfare of the metropolis.

Before considering the result at which the Council has arrived, it is desirable to recall that the Act of 1903 was intended to adapt the Education Act of 1902 to the particular needs of London. In detailing the methods to be followed in appointing an education committee, the earlier Act directs county councils to provide for the appointment by the council, on the nomination, where it appears desirable, of other bodies, of persons of experience in education, and of persons acquainted with the needs of the various kinds of schools in the area for which the council acts. It may be remarked that of $27 \mathrm{i}$ schemes approved by the Board of Education, some two-thirds provide for such co-opted members with expert knowledge. County councils are also directed to include women as well as men among members of the committee. But the number of members to constitute the committee is left to the discretion of the council.

Nก. 1789 vOL. 69]
The report now presented to the London County Council recoysilses the preparation of a scheme for the Education Committee as the chief duty which falls to the Council under the new Act, and the General Purposes Committee seems to have considered with due care, if not with complete understanding, schemes adopted in various local areas throughout the country, the model set them by the constitution of the London Technical Education Board, and the duties to be performed by the new Education Committee. The result of their deliberation has been strongly to " advise the Council to place two objects before it in constituting the Education Committee-( $x$ ) that the committee shall be one which will work harmoniously with the Council in developing a complete and well co-ordinated system of London education; and (2) that its constitution shall be such as to retain one of the greatest public interests under real public control as far as possible." With these objects little fault can be found, and it should have been possible to ensure both these ends and yet to have secured the assistance of co-opted members with special knowledge of the needs of every grade of education in London from the primary school to the university. Yet the report continues: "We propose that the committee shall consist of thirty-five members of the Council, with the chairman, vice-chairman and deputy-chairman, and that in accordance with the provision of the Act five women should be added, to be chosen for their experience in education. We think that the committee would be strengthened by the appointment during the term of the first committee of members of the present London School Board, and we recommend that power should be taken to add five such members. The first committee would, therefore, consist of forty-eight members." These recommendations of the committee were, after a debate consequent upon a proposed amendment, adopted, "only a few hands being held up against " them.

The scheme thus approved by the London County Council has still to be sanctioned by the Board of Education, and it may yet be hoped that an arrangement will be arrived at by which the committee-with its thirty-eight county councillors, five women and five present members of the School Board-will be srengthened by the inclusion of men fully conversant with the higher educational needs of London. The London County Council seems hardly to have been sufficiently impressed with the gigantic proportions of the task before it in co-ordinating the existing unrelated educational forces in the metropolitan area, and with the difficulties to be overcome, difficulties which can only be appreciated adequately by those familiar with London's peculiar educational requirements and deficiencies. And this is the more remarkable in view of the excellent work accomplished by its own Technical Education Board during the last decade, on which board representatives of the City and Guilds of London Institute, the London Trades Council, the trustees of the London Parochial Charities, as well as of associations of schoolmasters have acted, apparently with a due sense of their responsibility, though, during the debate upon the report, the chairman of the Technical Education Board, while testifying to the usefulness of having experts on the board, said " he always found that they did not act or vote with the same sense of responsibility as did the members of the Council on that body." His subsequent remarks, however, seemed rather to indicate that his view of responsibility meant the application of the test whether the ratepayers would approve every expenditure sanctioned by the Board. But one of the reasons for the inclusion of co-opted members with special knowledge is that there shall be a greater chance of having an educational policy 
adopted which aims first to secure a good system of education and regards a small increase of the rates as a secondary consideration.

Readers of NATURE do not need to be reminded of the paramount importance of improving and completing the facilities for higher technical and for university education in London. As Sir Michael Foster said in the House of Commons, during the second reading debate on the Education Act of 1903 , the new education committee and the reconstituted University of London must work together for the better education of the people of London, and the new committee must be interested in university as well as in secondary and elementary education. If, as the chairman of the General Purposes Committee remarked on proposing the adoption of the scheme outlined above, "the Education Act has any merit, it is that it co-ordinates the whole of the work of education in London." "This being so, the University of London must be regarded as the necessary complement of any system of primary and secondary education in London, and the work of the University on one hand and of the schools on the other must be fashioned so that one completes what the other has appropriately prepared. To ensure this the new committee should in its deliberations be assisted by broad-minded men familiar with the work and aspirations both of the schools and of the University, and the ordinary councillor, appointed to perform a variety of administrative duties, cannot be expected to possess the necessary knowledge and experience.

The Acts to be administered clearly specify that " the local education authority shall consider the educational needs of their area and take such steps as seem to them desirable, after consultation with the Board of Education, to supply or aid the supply of education other than elementary, and to promote the general coordination of all forms of education," and "education other than elementary" includes not only secondary but technical and university education. It is unnecessary to point out-it has been so often done in these columns - that to aid higher education is by no means to interfere with its administration. Higher education is a matter of national importance, and is properly governed only by men with special training and varied experience. Though it would be a misfortune for any education committee to hamper the work of, say, a senate of a university by unintelligent and unnecessary dictation, it should be the aim of every such authority to encourage, assist and advance university work by every means in its power, and this can alone be effected by the presence at its meetings of expert members.

In July last we described proposals made by Lord Rosebery in a letter to the chairman of the London County Council for the establishment of a great institute of technology in London, and in a subsequent issue we recorded the fact that the Council had, in certain circumstances, agreed to provide some $20,000 l$. a year towards the maintenance of the educational work of such an institute. In view of such an arrangement as this it is surely desirable that there should be upon the new education committee some members at least fully conversant with university and higher technical education, even on such low grounds as to ensure that the Council obtains a due return for its public-spirited policy. So, if it were necessary, other instances of the practical importance of including representative persons with special qualifications upon the new committee could be given. The fact is there seems to be an ingrained dislike in this country to make use of experts. While abroad the opinions of great men of science are, even in national councils, treated with honour and respect, with us they are more or less ignored, and the

$$
\text { No. I } 789 \text {, voi. 69] }
$$

example set in high places is followed by authorities of local importance only.

The London County Council is face to face with an opportunity, pregnant with possibilities, for equipping London educationally in a manner befitting the capital of a great Empire. But there is grave danger that the opportunity may be missed, and that London may continue ill-provided with facilities for the instruction of its sons and daughters in a manner to enable them properly to fulfil their destiny. So vital to our national welfare is this question of levelling up London's education that we can afford to neglect no means to ensure success; and to pass over and ignore completely the experience of those whose lives have been spent in studying educational and scientific requirements is a suicidal policy which we trust the good offices of the Board of Education will serve to avert.

\section{SLEEPING SICKNESS}

SLEEPING SICKNESS, or African lethargy, is a disease the history of which we can trace back no further than roo years. The first description that we know of is that of Winterbottom, who, writing of Sierra Leone in 1803 , said: "The Africans are very subject to a species of lethargy which they are much afraid of, as it proves fatal in every instance." The disease has been met with along the whole of the west coast of Africa from the mouth of the Senegal to as far south as S. Paolo de Loanda. Cases have also occurred in the French Antilles, due to importation of African natives. To what extent it prevailed along the west coast of Africa in bygone days it is now impossible to say, but even at the present time many of the French possessions are perhaps as seriously affected as Uganda now is.

It exists also in the Congo basin, but probably not at all to the same extent as at present in Uganda. Regarding its distribution and its epidemic outbursts we require further information. Leaving aside these questions, it may be well to describe first the disease itself. Of its incubation period, eight to eighteen months are possible limits, but on this point also our knowledge is deficient. For convenience sake the progress of the disease is generally divided into three stages.

First stage:-The most characteristic sig ${ }_{1}$ that a patient has contracted the disease is a change in the facial expression. The intelligent aspect of the healthy native is replaced by a dulness, a heaviness, an expression of apathy which makes it easy to pick out the sufferer. If examined more closely the temperature may be found to be raised, and the patient may complain of headache, of indefinite pains in the body, especially over the chest.

Second stage :-The dulness of expression deepens, the gait of the patient attracts attention, it is shuffling. When spoken to the patient replies with slow, thick, mumbling speech. His tongue trembles, and a shakiness appears in the hands. The face is puffy and saliva may dribble from the mouth. The pulse is quickened, the temperature is raised. The patient sits about listlessly and is more and more disinclined for exertion. He speaks only if spoken to, then he nods and becomes drowsy again, passing gradually into the

Third stage :-All the signs are now well marked. The patient is in a state of almost complete somnolence. $\mathrm{He}$ lies helpless on his mat, oblivious of all around him, with filthy ulcers covering his emaciated body; thus the unfortunate being passes into a condition of complete coma-and death.

The whole course of the disease may last six months, often only two or three, and seldom twelve, and it is as 